\title{
Supplementing diets of Awassi ewes with olive cake and tomato pomace: on-farm recovery of effects on yield, composition and fatty acid profile of the milk
}

\author{
Souheila Abbeddou • Barbara Rischkowsky • \\ Muhi El-Dine Hilali • Muhammed Haylani • \\ Hans Dieter Hess • Michael Kreuzer
}

Received: 21 August 2014 / Accepted: 30 September 2014 / Published online: 18 October 2014

(C) Springer Science+Business Media Dordrecht 2014

\begin{abstract}
Two experiments were carried out in Syria with the purpose of investigating to which extent the effects of including $30 \%$ olive cake (replacing parts of forage and concentrate) or tomato pomace (replacing concentrate) in the diet, described under controlled on-station conditions, can be recovered on farm. A total of 180 lactating Awassi ewes (three farms per experiment, 15 ewes per treatment) were fed either control diets or test feed diets over a period of 7 weeks. Milk yield was measured bi-weekly and milk composition was analysed for gross physicochemical composition and fatty acid (FA) profile. Both feeds reduced milk yield (-10\%) and milk protein content, whereas milk fat content was increased by tomato pomace. Both feeds resulted in similar changes in milk FA profile, namely less saturated and polyunsaturated FA and more monounsaturated FA including 18:1 trans FA. Tomato pomace and olive cake also resulted in increased $n-6: n-3$ FA ratios, while the proportion of the conjugated linoleic acids was not affected by either treatment. In
\end{abstract}

S. Abbeddou $\cdot$ M. Kreuzer $(\bowtie)$

ETH Zurich, Institute of Agricultural Sciences, Universitätstrasse 2, 8092 Zurich, Switzerland

e-mail: Michael.kreuzer@inw.agrl.ethz.ch

\section{B. Rischkowsky}

International Center for Agricultural Research in the Dry Areas (ICARDA), P.O. Box 5689, Addis Ababa, Ethiopia

\section{E.-D. Hilali}

International Center for Agricultural Research in the Dry Areas (ICARDA), P.O. Box 950764, Amman, Jordan

\author{
M. Haylani \\ International Center for Agricultural Research in the Dry Areas \\ (ICARDA), Aleppo, Syria \\ H. D. Hess \\ Institute for Livestock Sciences, Agroscope, P.O. Box 64, \\ 1725 Posieux, Switzerland
}

conclusion, the response of the ewes on farm was clear and similar in nature for most of milk-related traits as that found on station, but lower in magnitude.

Keywords Sheep $\cdot$ Milk $\cdot$ Fatty acid $\cdot$ Olive cake . Tomato pomace $\cdot$ Syria

\section{Introduction}

In Mediterranean countries, large amounts of by-products are available from olive oil production and tomato processing. Although a number of studies showed that olive cake and tomato pomace have feeding potential, their actual feeding value under practical farming conditions is not well known. Increased knowledge about the effects of the use of alternative feeds at farm level could increase the adoption of these feed alternatives by farmers and promote their marketing as feeds. Research on the effects of such feeds on milk yield and other animal performance traits has been intensified since the reviews by Molina-Alcaide and Yáñez-Ruiz (2008) and Vasta et al. (2008). Various studies investigated the effect of including olive cake in various forms in the diet of lactating ewes (Hadjipanayiotou 1999; Chiofalo et al. 2004; Vargas-BelloPérez et al. 2013a) and other dairy animals (Molina-Alcaide et al. 2010, Faye et al. 2013, Terramoccia et al. 2013), and in growing lambs (e.g., Taheri et al. 2013). However, few have investigated the effect of tomato pomace (Romano et al. 2010; Romero-Huelva et al. 2012). In these experiments, between 2 and $25 \%$ of the diet were replaced with these alternative feeds. A previous controlled on-station experiment demonstrated that $30 \%$ of a common diet for indigenous fat-tailed dairy Awassi sheep can be replaced by any of these two feeds without major impairment of performance (Abbeddou et al. 2011b). Among the two feeds, tomato pomace had been 
previously shown to be equivalent to other concentrate ingredients while olive cake ranged in between low-quality forage and concentrate ingredients (Abbeddou et al. 2011a). Additionally, at $30 \%$ proportion in the diet (Abbeddou et al. 2011b), the two alternative feeds shifted the fatty acid (FA) profile of the milk towards that considered beneficial for human health $(\mathrm{DACH}, 2000$; Jutzeler van Wijlen and Colombani 2010).

The hypothesis tested in the present study was that the effects on animal performance and FA profile of including olive cake or tomato pomace at $30 \%$ in the diet, as found before in dairy ewes under controlled conditions (Abbeddou et al. 2011b), can be fully recovered under field conditions. In order to exclude farm effects, test diets were used on three farms each with indigenous fat-tailed Awassi sheep, the most common sheep breed in the region.

\section{Materials and methods}

\section{Experimental farms and animals}

The study took place in 2009 in the Aleppo province of Syria. In the year preceding the experiments, farmers in the area were approached to determine their interest and eligibility to participate in an up-scaling experiment testing the effects of replacing part of the traditional diet with alternative feeds at farm level. In a series of meetings, the purpose of the experiments and the criteria for including farms were explained. These were the availability of at least 30 ewes in an age range between 3 and 5 years and at least in their second gestation and the willingness of the farmers to feed the test diets for 2 months once the experiment started. Additionally, questions raised by the farmers about feed safety and potential risks for milk production were answered. Eventually, six farms from the villages Abu Jabar, Khirbat Al-Dib and Qdayria were selected for the experiment. The farmers owned from 55 to 300 ewes in the age range of 3 to 6 years whereof between 51 and 64 were subjected to data collection for consideration to be selected as experimental animals. All farms fed straw as dry season fodder and concentrate mostly prepared from barley or other cereals, wheat bran and sugar beet pulp. In order to minimize mistakes in feed allocation, treatments per farm were limited to two (control vs. test diet), resulting in three farms per experiment.

The unimodal rainy season leads to a mating regime with a relatively narrow lambing season, which was conducive for limiting the duration of the experimental period. On all farms selected, in the mating season, extra cottonseed meal was provided to the ewes in order to promote conception and thereby shorten the lambing period. In January 2009, when the ewes started lambing, the experimental farms were first visited and every second week from then on. The development of the lambs' body weight (BW) was considered in order to determine the date of weaning, i.e. the start of the experiment. On day 0 of the experiment (on average $62 \pm$ 16 days after lambing), all suitable ewes were weighed after $12 \mathrm{~h}$ had passed from the last feeding/water consumption. Body weight, lambing date, milk yield and gross composition of the morning milk were used to eventually select 30 ewes per farm for the experiments (180 ewes in total). On each farm, half of the ewes were assigned to a control group, the other half to one of the two test diet groups (olive cake diet in experiment 1 , tomato pomace in experiment 2 ) in a way which balanced treatment averages for a number of performance traits.

\section{Feeds and feeding}

New batches from the already tested on-station feeds, i.e. olive cake and tomato pomace, were purchased for this study. The residue from the first pressing of green olives, consisting of skin, pulp and stones, was obtained from a traditional cold pressing olive oil factory in Afrin, Syria, during November and December 2008. The residue was dried indoors at room temperature. Tomato processing residues were bought in summer 2008 and dried in the shade. Farmers used their own barley straw. All other dietary ingredients (Table 1) used in these experiments had also been obtained as complete batches and were the same as those that had been employed for the previous assessments (see more details in Abbeddou et al. 2011a, b). Without either olive cake or tomato pomace, the composition was the same as that used earlier (Abbeddou et al. 2011b), except that wheat grain was replaced by barley grain. This control diet basically represented the traditional farm practice in terms of ingredients and composition.

The diets were composed of concentrate and straw in a ratio of 7:3. Proportionately, $3 / 7$ of the traditional concentrate, predominantly consisting of sugar beet pulp, wheat bran and cottonseed meal, was replaced by barley grain and olive cake $(2 / 3)$ or by tomato pomace in the test diets (Table 1). Like in Abbeddou et al. (2011b), the test diets contained less metabolizable energy (ME), calculated from in vitro organic matter digestibility (IVOMD) following Abbeddou et al. (2011a), than the control diet, and this was especially true for the olive cake-based diet. The complete diets were balanced for crude protein $(\mathrm{CP})$ by adding urea to the concentrate. Molasses were added to all diets to improve palatability. All concentrates were supplemented with a vitaminized mineral mix. Water was supplied at ad libitum access.

Ewes on the experimental farms had not started grazing when the experiment started because of exceptionally poor pastures as a consequence of low precipitation. Following farmer traditions, the ewes were allowed to graze later on in 
Table 1 Nutritional value of the ingredients and composition of experimental diets ( $\%$ of dry matter)

\begin{tabular}{|c|c|c|c|c|c|}
\hline \multirow[b]{2}{*}{ Trait } & \multicolumn{2}{|l|}{ Ingredient } & \multicolumn{3}{|l|}{ Diet } \\
\hline & Crude protein & Metabolizable energy $^{a}$ & Control & Olive cake & Tomato pomace \\
\hline \multicolumn{6}{|l|}{ Ingredients } \\
\hline Olive cake & 6.1 & 2.4 & - & 29.8 & - \\
\hline Tomato pomace & 20.3 & 6.0 & - & - & 29.8 \\
\hline Barley grain & 13.7 & 11.2 & 9.9 & 29.8 & 19.8 \\
\hline Sugar beet pulp & 10.3 & 10.6 & 29.8 & - & 5.0 \\
\hline Wheat bran & 17.4 & 10.3 & 9.9 & - & - \\
\hline Cotton seed meal & 38.5 & 7.5 & 19.8 & 9.9 & 4.9 \\
\hline Molasses & 6.2 & 11.7 & - & 9.9 & 9.9 \\
\hline Mineral-vitamin premix ${ }^{\mathrm{b}}$ & - & - & 0.8 & 0.8 & 0.8 \\
\hline Barley straw & 6.1 & 6.7 & 29.8 & 19.8 & 29.8 \\
\hline \multicolumn{6}{|l|}{ Protein and energy contents } \\
\hline Crude protein & & & 17.6 & 17.5 & 17.7 \\
\hline Metabolizable energy $^{a}$ & & & 8.8 & 7.3 & 8.1 \\
\hline
\end{tabular}

Diets were individually supplemented with urea at levels of $0.7,2.0$ and $1.4 \%$ of dry matter for control, olive cake and tomato pomace diets, respectively ${ }^{\mathrm{a}} \mathrm{MJ} / \mathrm{kg}$ dry matter

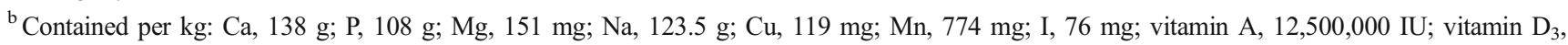
300,000 IU; vitamin E, $0.5 \mathrm{~g}$

addition to receiving the experimental diet, but this was only for few hours/day. According to estimates made by Hilali et al. (2011), grazing natural pastures in the area may cover up to $25 \%$ of the animal requirements. However, although not measured, it is likely that the grass intake was much lower in 2009 than in average years.

The quantities of straw and concentrate to be handed over weekly to the farmers were calculated based on the dry matter (DM) and CP analyses carried out at ICARDA and ME calculations, and weighed and carefully mixed manually at ICARDA. On each farm, one family member was trained by the experimenters to weigh the feeds and to supervise that feeding was performed exactly to the experimental schedule. Starting from day 0 , the experimental groups of ewes were separated from the entire flock and fed exclusively the experimental diets. A 14-day transition period from the diet used before, which was considered to be part of the entire experiment, consisted of gradually adapting the animals to higher amounts of feed in general and especially the unfamiliar test feeds. Accordingly, on experimental day 0 , only $1 \mathrm{~kg}$ diet DM (concentrate to straw ratio, 2:1) was offered per ewe, which was increased to $2 \mathrm{~kg} \mathrm{DM} /$ ewe on day 1 . From day 9 to day 14 , the ewes were offered $2.3 \mathrm{~kg} \mathrm{DM} /$ day and reached $2.5 \mathrm{~kg}$ $\mathrm{DM} /$ day from day 15 to day 50 . This meant that after 2 weeks, $0.75 \mathrm{~kg}$ straw and $1.75 \mathrm{~kg}$ concentrate per head per day were provided, except for the olive cake group where this was $0.5 \mathrm{~kg}$ straw and $2.0 \mathrm{~kg}$ concentrate. Half of the daily portion was offered at $09.00 \mathrm{a} . \mathrm{m}$. and the other half at 05.00 p.m.; this was always done directly after milking.
Data recording and sample collection

Dietary ingredients were sampled for analysis before the experiment started. On day 0 and after the 7 weeks of experiment, BW was measured by a mechanical balance. This was done after milking and before feeding. On day 0 , and at the end of weeks 1, 3, 5 and 7, milk yield was determined by a volumetric cylinder during two milking events starting at 08.00 a.m. and 04.00 p.m. Milking was done manually by women. Samples of morning milk $(50 \mathrm{ml})$ were put into a cooling box $\left(4^{\circ} \mathrm{C}\right)$ and transported to ICARDA's laboratory at the end of the sampling where they were immediately analysed for their constituent composition. Milk subsamples from 10 random ewes out of the 15 ewes per treatment per farm obtained on day 0 and at the end of weeks 1 and 7 of the experiment were immediately stored at $-20{ }^{\circ} \mathrm{C}$ for later FA analysis.

All procedures involving the animals followed the international guiding principles published by the Council for International Organizations of Medical Sciences and the International Council for Laboratory Animal Science (2012).

Laboratory analyses

Feeds were analysed for their proximate contents by standard methods (AOAC 1997). These included DM, CP (AOAC 977.02; using Kjeldahl unit Vapodest 30, C. Gerhardt, GmbH\&Co., KG, Königswinter, Germany) and IVOMD (Tilley and Terry 1963). Contents of fat, protein, lactose, total 
solids (TS) and solids non-fat (SNF) in milk were measured by the Milkoscan 133 B (Foss Electric, Denmark). In the same individual milk samples, electrical conductivity (EC; Microprocessor EC/TDS Meter, HI98360), $\mathrm{pH}$ ( $\mathrm{pH}$ meter, HI113), both from Hanna Instruments, Padovana, Italy, and density (density meter, DMA35, PAAR, Graz, Austria) were analysed. Energy-corrected milk (ECM; kg/day) was calculated based on the ALP (2008) formula as

$\operatorname{ECM}(\mathrm{kg} / \mathrm{d})$

$=\operatorname{Milk}(\mathrm{kg} / \mathrm{d}) \mathrm{x}\left[0.38^{\mathrm{x}}\right.$ fat $(\%)+0.24^{\mathrm{x}}$ protein $(\%)+0.17^{\mathrm{x}}$ lactose $\left.(\%)\right] / 3.14$

For FA analysis, milk samples were thawed in a water bath at $37^{\circ} \mathrm{C}$ and gently mixed to achieve a homogenous distribution of the milk fat. The FA were extracted and analysed as outlined by Molkentin and Precht (2000), with the same equipment (gas chromatograph GC 2010 with GCsolution program, Shimadzu, Kyoto, Japan; CP-Sil88-fused silica capillary column SPTM-2560 with $100 \mathrm{~m} \times 0.25 \mathrm{~mm}$ ID, $0.20-\mu \mathrm{m}$ film, Supelco, Bellefonte, PA, USA) and protocol as described in detail in Abbeddou et al. (2011b).

\section{Statistical analysis}

Data was analysed by repeated measurement analysis using the MIXED procedure of SAS (2009) and assuming a compound symmetric structure. The fixed effects considered were diet, period (weeks 1, 3, 5 and 7, except for FA with weeks 1 and 7 and BW with week 7 only) and the interaction between these two factors (except for BW). Farm was included in the model as random effect. All experimental data were adjusted for baseline records measured at day 0 (covariate). Data obtained on day 0 was statistically analysed to control whether there were differences in treatment allocation. Farm was considered. Tables display least squares means and standard errors of the mean.

\section{Results and discussion}

On average over both groups, BW (kg), initial days in milk, (energy-corrected) milk yield (g/day) and contents (\%) of TS, SNF, fat, protein and lactose in milk were 47.0, 62.6, 768, $15.5,11.8,3.76,5.62$ and 5.42, respectively, in experiment 1 . In experiment 2 , the corresponding initial values were 42.3 , $60.7,997,15.8,11.5,4.35,5.39$ and 5.36, respectively. None of the baseline group means did significantly differ.

Treatment effects on performance and general milk quality traits

All ewes gained weight during the two experiments, but this significantly less with the tomato pomace diet as compared to control (Table 2). The ECM yield was in the order of 1.1 to $1.3 \mathrm{~kg}$ /day. It increased from the preexperimental to the experimental diet in all groups. These effects were likely the result of the higher amount of feed offered, even though the diets had a lower concentrate proportion than the preexperimental diets. The latter also resulted in a significant increase in milk fat content compared to the baseline values.

Olive cake-fed ewes produced significantly less ECM (9\%) and milk protein (14\%) than their control group. The corresponding values for the tomato pomace-fed ewes were -10 and $-16 \%$. Milk fat yield was significantly reduced only after olive cake feeding during the entire experiment period. The average decline in ECM yield was of the same magnitude as that found on station by Abbeddou et al. (2011b) with -11 and $-6 \%$ ECM when feeding olive cake- and tomato pomacecontaining diets. However, in that study, this trend was not significant maybe because of the comparably smaller sample size. Additionally, in the present investigation, the tomato pomace diet was no longer superior to the olive cake diet (analysis between the two groups not shown). RomeroHuelva et al. (2012) found a trend towards lower milk yield with tomato pomace, too, even though it was included at a proportion of only $12.5 \%$ in DM. Olive cake is particularly low in digestibility and energy content (Abbeddou et al., 2011a), but this had been taken into account when designing the corresponding test diet. The feeding value of olive cake could clearly increase if a de-stoning step was implemented in olive processing (e.g., Chiofalo et al. 2004). Although most of studies were carried out on animals well adapted to the dry conditions, the present effects on the performance of the two feeds are difficult to compare with those found by others in dairy animals since (i) typically much lower proportions were included in these diets, (ii) concentrate or forages or both were replaced, (iii) feeds were given in different forms (ensiled, dried, combinations) and (iv) sometimes species other than sheep were tested. This may help to explain why adverse effects of olive cake on milk yield were only found in one study including only $10-12 \%$ olive cake in diet as fed (Molina-Alcaide et al. 2010), whereas no negative effect was reported by Terramoccia et al. (2013) and even a trend towards higher performance was found by Hadjipanayiotou (1999), Chiofalo et al. (2004) and Faye et al. (2013).

The declines in milk protein content found with both test diets were consistent with the reduced dietary energy supply corroborating the findings of milk yield declines. Different from the olive cake diet, the tomato pomace diet promoted milk fat content. This different response may be explained by certain structural properties of fibrousness of both feeds and the concomitant reduction in straw proportion in the olive cake diet. Total solids and lactose contents were not significantly affected by the test diets. The tomato pomace diet led to significant declines of $\mathrm{pH}$ and milk density, while both diets 
Table 2 Effect of diet type and measurement period (end of weeks 1, 3, 5 and 7 of experiment; body weight (BW) only end of week 7) on BW changes, milk yield and physicochemical properties of the milk ( $n=45$ per period and treatment, $n=720$ in total)

\begin{tabular}{|c|c|c|c|c|c|c|c|c|c|c|c|c|}
\hline \multirow[b]{3}{*}{ Trait } & \multicolumn{6}{|c|}{ Olive cake experiment } & \multicolumn{6}{|c|}{ Tomato pomace experiment } \\
\hline & \multirow[b]{2}{*}{ Control } & \multirow[b]{2}{*}{$\begin{array}{l}\text { Olive } \\
\text { cake }\end{array}$} & \multirow[b]{2}{*}{ SEM } & \multicolumn{3}{|l|}{$P$ value } & \multirow[b]{2}{*}{ Control } & \multirow[b]{2}{*}{$\begin{array}{l}\text { Tomato } \\
\text { pomace }\end{array}$} & \multirow[b]{2}{*}{ SEM } & \multicolumn{3}{|l|}{$P$ value } \\
\hline & & & & $\begin{array}{l}\text { Diet } \\
\text { (D) }\end{array}$ & $\begin{array}{l}\text { Period } \\
\text { (P) }\end{array}$ & $\mathrm{D} \times \mathrm{P}$ & & & & $\begin{array}{l}\text { Diet } \\
\text { (D) }\end{array}$ & $\begin{array}{l}\text { Period } \\
\text { (P) }\end{array}$ & $\mathrm{D} \times \mathrm{P}$ \\
\hline BW change (g/day) & 154 & 138 & 7.1 & 0.238 & - & - & 207 & 179 & 7.1 & 0.005 & - & - \\
\hline \multicolumn{13}{|l|}{ Milk yield (g/day) } \\
\hline Total ECM & 1187 & 1092 & 23.9 & 0.008 & 0.001 & 0.355 & 1286 & 1155 & 22.7 & $<0.001$ & $<0.001$ & 0.163 \\
\hline Change in ECM & 420 & 324 & 20.6 & 0.008 & 0.001 & 0.355 & 288 & 157 & 21.2 & $<0.001$ & $<0.001$ & 0.163 \\
\hline Fat & 48.2 & 44.2 & 0.94 & 0.014 & 0.031 & 0.584 & 52.4 & 50.2 & 0.99 & 0.199 & $<0.001$ & 0.423 \\
\hline Protein & 50.1 & 43.0 & 0.94 & $<0.001$ & $<0.001$ & 0.046 & 51.2 & 42.9 & 0.82 & $<0.001$ & $<0.001$ & 0.107 \\
\hline \multicolumn{13}{|l|}{ Milk composition (\%) } \\
\hline Total solids & 17.4 & 17.8 & 0.13 & 0.091 & $<0.001$ & 0.968 & 17.6 & 17.4 & 0.11 & 0.288 & $<0.001$ & 0.224 \\
\hline Solids non-fat & 11.7 & 11.8 & 0.07 & 0.698 & 0.136 & 0.147 & 11.7 & 11.2 & 0.05 & $<0.001$ & 0.015 & 0.260 \\
\hline Fat & 5.85 & 5.99 & 0.075 & 0.175 & $<0.001$ & 0.006 & 5.91 & 6.33 & 0.069 & $<0.001$ & $<0.001$ & 0.138 \\
\hline Protein & 5.96 & 5.72 & 0.028 & $<0.001$ & $<0.001$ & 0.357 & 5.74 & 5.44 & 0.033 & $<0.001$ & $<0.001$ & 0.995 \\
\hline Lactose & 5.39 & 5.34 & 0.017 & 0.103 & $<0.001$ & 0.857 & 5.28 & 5.17 & 0.017 & $<0.001$ & $<0.001$ & 0.921 \\
\hline $\mathrm{pH}$ & 6.61 & 6.59 & 0.009 & 0.125 & $<0.001$ & 0.785 & 6.61 & 6.58 & 0.006 & 0.009 & $<0.001$ & 0.945 \\
\hline Electrical conductivity (mSv) & 4.16 & 4.24 & 0.021 & 0.040 & $<0.001$ & 0.194 & 4.32 & 4.36 & 0.020 & 0.249 & $<0.001$ & 0.165 \\
\hline Density & 1.037 & 1.035 & 0.0010 & 0.191 & 0.531 & 0.436 & 1.035 & 1.034 & 0.0002 & $<0.001$ & $<0.001$ & 0.774 \\
\hline
\end{tabular}

$E C M$ energy-corrected milk, SEM standard error of mean

resulted in an increased milk EC. However, these changes are not likely to be of practical relevance for instance for manufacturing yoghurt and cheese. Most studies did not report significant changes in milk protein and fat contents with either olive cake (Chiofalo et al. 2004; Molina-Alcaide et al. 2010; Abbeddou et al. 2011b; Faye et al. 2013; Terramoccia et al. 2013; Vargas-Bello-Pérez et al. 2013a) or tomato pomace (Romero-Huelva et al. 2012). Hadjipanayiotou (1999) noted elevated milk fat contents with olive cake and, consistent with the present study, Abbeddou et al. (2011b) found a reduced milk protein content with tomato pomace. Except from one case, there were no significant diet type $\times$ period interactions in the present study.

Treatment effects on the fatty acid profile of the milk fat

Diet type had a significant influence on the proportions of the majority of the FA in milk fat in both experiments (Table 3). Feeding olive cake and tomato pomace diets significantly reduced proportions of total saturated FA, total short-chain and total medium-chain FA, 16:0 and 18:2 $c 9, c 12$. Both diet types significantly increased 18:0 proportions, which is the terminal product of biohydrogenation of unsaturated C18 FA, as well as proportions of 18:1 $c 9$ and all trans-18:1 FA except 18:1 $t 11$. Concerning total and individual conjugated linoleic acids (CLA), there was no response to the olive cake diet whereas the tomato pomace diet resulted in different responses (increased proportions of 18:2 $c 9, t 12$ and 18:2 $c 9, t 13$; decreased proportions of $18: 2 t 11, c 15$ and $18: 2$ $c 9, c 11$; no change in the two remaining isomers) leading to unchanged total CLA proportions. Polyunsaturated FA with $>2$ double bonds remained unaffected by the test diets except for a decline in $20: 5 c 5, c 8, c 11, c 14, c 17$ with both treatments. With both test diets, proportions of monounsaturated FA increased. Those of polyunsaturated FA were significantly decreased with olive cake. Total $n$-3 FA slightly declined and, with the tomato pomace diet, total $n-6$ FA significantly increased. The calculated $n-6: n-3$ ratio significantly increased after feeding olive cake (from 1.4 to 1.6) and even to a larger extent after feeding tomato pomace (from 1.5 to 2.3). Still, the threshold of 5 as is desired for human diets (DACH 2000) was never exceeded. The ratios found in the present study were clearly lower than those reported by Abbeddou et al (2011b) in the on-station experiment (ratios ranged between 8.5 and 10.5 with traditional and olive cake- and tomato pomacesupplemented diets).

From the results, it can be deducted that an extensive ruminal biohydrogenation of the lipids present in both test feeds took place. Biohydrogenation was even complete to a substantial degree as confirmed by the elevated 18:0 proportions. As the biohydrogenation intermediates 18:1 trans and CLA need polyunsaturated FA as precursors (Chilliard et al. 
Table 3 Effect of diet type and measurement period (end of weeks 1 and 7 of experiment) on the proportions of fatty acids in milk fat (\% of total fatty acid methyl esters) $(n=30$ per period per treatment, $n=240$ in total)

\begin{tabular}{|c|c|c|c|c|c|c|c|c|c|c|c|c|}
\hline \multirow[b]{3}{*}{ Fatty acid } & \multicolumn{6}{|c|}{ Olive cake experiment } & \multicolumn{6}{|c|}{ Tomato pomace experiment } \\
\hline & \multirow[b]{2}{*}{ Control } & \multirow[b]{2}{*}{$\begin{array}{l}\text { Olive } \\
\text { cake }\end{array}$} & \multirow[b]{2}{*}{ SEM } & \multicolumn{3}{|l|}{$P$ value } & \multirow[b]{2}{*}{ Control } & \multirow[b]{2}{*}{$\begin{array}{l}\text { Tomato } \\
\text { pomace }\end{array}$} & \multirow[b]{2}{*}{ SEM } & \multicolumn{3}{|l|}{$P$ value } \\
\hline & & & & $\begin{array}{l}\text { Diet } \\
\text { (D) }\end{array}$ & $\begin{array}{l}\text { Period } \\
\text { (P) }\end{array}$ & $\mathrm{D} \times \mathrm{P}$ & & & & $\begin{array}{l}\text { Diet } \\
\text { (D) }\end{array}$ & $\begin{array}{l}\text { Period } \\
\text { (P) }\end{array}$ & $\mathrm{D} \times \mathrm{P}$ \\
\hline $16: 0$ & 26.6 & 24.5 & 0.25 & $<0.001$ & $<0.001$ & $<0.001$ & 27.8 & 25.5 & 0.23 & $<0.001$ & 0.318 & 0.176 \\
\hline $18: 0$ & 10.5 & 12.2 & 0.26 & $<0.001$ & $<0.001$ & $<0.001$ & 10.5 & 13.6 & 0.23 & $<0.001$ & 0.877 & 0.993 \\
\hline $18: 1 c 9$ & 15.8 & 19.9 & 0.36 & $<0.001$ & $<0.001$ & $<0.001$ & 14.6 & 19.7 & 0.30 & $<0.001$ & $<0.001$ & 0.231 \\
\hline $18: 1 c 12$ & 0.241 & 0.227 & 0.0050 & 0.104 & 0.924 & 0.150 & 0.263 & 0.429 & 0.0099 & $<0.001$ & $<0.001$ & 0.089 \\
\hline Total 18:1 cis & 16.8 & 21.1 & 0.37 & $<0.001$ & $<0.001$ & $<0.001$ & 15.7 & 21.2 & 0.32 & $<0.001$ & $<0.001$ & 0.268 \\
\hline $18: 1$ t4 to $t 9$ & 0.524 & 0.915 & 0.0299 & $<0.001$ & $<0.001$ & $<0.001$ & 0.479 & 0.788 & 0.0170 & $<0.001$ & 0.014 & 0.108 \\
\hline $18: 1 t 10$ & 0.401 & 0.568 & 0.0160 & $<0.001$ & 0.002 & $<0.001$ & 0.345 & 0.512 & 0.0111 & $<0.001$ & 0.001 & 0.481 \\
\hline $18: 1 t 11$ & 1.13 & 1.13 & 0.027 & 0.899 & $<0.001$ & 0.581 & 1.23 & 1.18 & 0.033 & 0.362 & $<0.001$ & 0.016 \\
\hline Total 18:1 trans & 2.37 & 3.01 & 0.063 & $<0.001$ & $<0.001$ & $<0.001$ & 2.38 & 2.99 & 0.053 & $<0.001$ & 0.034 & 0.032 \\
\hline $18: 2 c 9, \mathrm{c} 12$ & 2.59 & 2.12 & 0.044 & $<0.001$ & $<0.001$ & $<0.001$ & 2.60 & 2.32 & 0.033 & $<0.001$ & $<0.001$ & 0.840 \\
\hline $18: 2 c 9, c 11$ & 0.085 & 0.076 & 0.0030 & 0.090 & $<0.001$ & 0.285 & 0.074 & 0.053 & 0.0036 & 0.001 & $<0.001$ & 0.047 \\
\hline $18: 2 c 9, t 13$ & 0.276 & 0.281 & 0.0059 & 0.652 & $<0.001$ & 0.266 & 0.284 & 0.367 & 0.0085 & $<0.001$ & 0.001 & 0.022 \\
\hline $18: 2 c 9, t 12$ & 0.092 & 0.097 & 0.0023 & 0.271 & 0.837 & 0.226 & 0.100 & 0.127 & 0.0031 & $<0.001$ & 0.370 & 0.227 \\
\hline $18: 2 t 11, c 15$ & 0.178 & 0.172 & 0.0065 & 0.517 & 0.001 & 0.887 & 0.192 & 0.156 & 0.0075 & 0.002 & $<0.001$ & 0.078 \\
\hline $18: 2 c 9, t 11$ & 0.519 & 0.533 & 0.0112 & 0.506 & $<0.001$ & 0.159 & 0.545 & 0.579 & 0.0128 & 0.161 & 0.127 & 0.005 \\
\hline $18: 2 t 9, t 11$ & 0.051 & 0.049 & 0.0024 & 0.566 & $<0.001$ & 0.951 & 0.049 & 0.053 & 0.0033 & 0.539 & 0.692 & 0.231 \\
\hline Total CLA & 0.656 & 0.656 & 0.0131 & 0.998 & $<0.001$ & 0.127 & 0.668 & 0.686 & 0.0148 & 0.511 & 0.837 & 0.002 \\
\hline $18: 3 c 9, c 12, c 15$ & 0.569 & 0.539 & 0.0246 & 0.140 & $<0.001$ & 0.064 & 0.451 & 0.437 & 0.0184 & 0.590 & 0.059 & 0.363 \\
\hline $20: 5 c 5, c 8, c 11, c 14, c 17$ & 0.073 & 0.064 & 0.0030 & 0.044 & $<0.001$ & 0.632 & 0.057 & 0.047 & 0.0018 & 0.001 & 0.814 & 0.519 \\
\hline $22: 6 c 4, c 7, c 10, c 13, c 16, c 19$ & 0.041 & 0.031 & 0.0048 & 0.295 & 0.466 & 0.236 & 0.034 & 0.029 & 0.0037 & 0.472 & 0.247 & 0.239 \\
\hline Total $n-3$ & 1.15 & 1.08 & 0.013 & 0.059 & $<0.001$ & 0.083 & 0.98 & 0.90 & 0.033 & 0.072 & 0.274 & 0.475 \\
\hline Total $n-6$ & 1.41 & 1.44 & 0.019 & 0.343 & 0.015 & 0.741 & 1.39 & 1.88 & 0.034 & $<0.001$ & $<0.001$ & 0.749 \\
\hline$n-6: n-3$ ratio & 1.42 & 1.61 & 0.071 & 0.030 & $<0.001$ & 0.048 & 1.55 & 2.34 & 0.069 & $<0.001$ & $<0.001$ & 0.943 \\
\hline SCFA & 15.1 & 13.9 & 0.21 & 0.001 & $<0.001$ & 0.160 & 15.3 & 12.3 & 0.26 & $<0.001$ & $<0.001$ & 0.168 \\
\hline MCFA & 44.6 & 39.7 & 0.47 & $<0.001$ & $<0.001$ & $<0.001$ & 45.4 & 39.6 & 0.38 & $<0.001$ & 0.050 & 0.392 \\
\hline SFA & 70.4 & 66.0 & 0.41 & $<0.001$ & $<0.001$ & 0.001 & 71.3 & 65.3 & 0.39 & $<0.001$ & $<0.001$ & 0.897 \\
\hline MUFA & 21.4 & 26.1 & 0.40 & $<0.001$ & $<0.001$ & $<0.001$ & 20.3 & 26.2 & 0.35 & $<0.001$ & $<0.001$ & 0.677 \\
\hline PUFA & 5.70 & 5.12 & 0.068 & $<0.001$ & $<0.001$ & $<0.001$ & 5.48 & 5.38 & 0.067 & 0.386 & $<0.001$ & 0.897 \\
\hline
\end{tabular}

CLA conjugated linoleic acids, MCFA medium-chain fatty acids, $M U F A$ monounsaturated fatty acids, $P U F A$ polyunsaturated fatty acids, $S C F A$ shortchain fatty acids, $S E M$ standard error of mean, SFA saturated fatty acids

2007), it was astonishing that the tomato pomace diet, rich in these FA, did not result in an increase in total CLA and not in a clearer increase in the 18:1 trans FA than the olive cake diet. Several secondary constituents, abundant in olive cake, may have (partially) inhibited biohydrogenation (e.g., Vasta and Luciano 2011). As 18:1 $c 9$ is not a biohydrogenation intermediate (Chilliard et al. 2007), other pathways could be involved in elevating 18:1 $c 9$ proportions in the milk, such as a direct transfer from feed. With tomato pomace, an up-regulated desaturation of 18:0, probably in the mammary gland, has to be assumed as a consequence of the greater metabolic supply with 18:0 (Abbeddou et al. 2011b).
In the present study, overall the response to the olive cake and tomato pomace diets in the FA profile was quite similar, except that of certain CLA isomers. This similarity in response was unexpected because the two test feeds clearly differ in FA profile and, with that, the resulting diets. The major FA ( $\%$ of total FA) found in batches of similar origin of olive cake by Abbeddou et al. (2011b) was 18:1 $c 9(64.2 \%)$, whereas it was $18: 2 c 9, c 12(55.1 \%)$ in tomato pomace. The corresponding FA proportions (\%) in milk described by Abbeddou et al. (2011b) in the total diet FA (control, olive cake and tomato pomace diets) were 14.2, 27.0 and 13.7 for $18: 1 c 9$ and 29.8, 27.0 and 36.5 for $18: 2 c 9, c 12$, respectively. 
In the present experiments, type and direction of response to both olive cake and tomato pomace in key FA was to a large degree the same as that found by Abbeddou et al. (2011b), but the magnitude of the change was mostly only half as high. It seems that a part of the effect was diluted by other factors such as grazing, and this includes the control as well. The effects olive cake had on milk FA profile partially agreed with the findings by others in milk of ewes (Chiofalo et al. 2004; Abbeddou et al. 2011b; Vargas-Bello-Pérez et al. 2013a), goats (Molina-Alcaide et al. 2010), buffaloes (Terramoccia et al. 2013) and camels (Faye et al. 2013), where the level of effect sometimes was small owing to low dietary olive cake proportions. The present results were additionally confirmed by quite similar responses of milk FA to pure olive oil supplementation (Gómez-Cortés et al. 2008; Vargas-Bello-Pérez et al. 2013b). Concerning the effects of tomato pomace on milk FA profile, the results of other studies (Romano et al. 2010; Romero-Huelva et al. 2012) disagreed quite strongly with those of Abbeddou et al. (2011b) and the present investigation. When the level and direction of effect of both test feeds disagreed with other findings, then it was predominantly in the proportions of $18: 2 c 9, c 12$ and $n-6: n-3$ ratio and, with olive cake, in CLA. This could be the result of differences either between control diets or in the FA profile of the test feeds. In the present study, there were a number of significant treatment $\times$ period interactions in FA with olive cake, indicating that the level of the olive cake effect changed with time.

\section{Conclusions}

It was possible to show with Awassi sheep that the nature of the effects of two food industry by-products, obtained under controlled research station conditions, can actually be recovered very closely on private farms. However, concerning the desired changes in milk fatty acid profile, the level of effect was mostly only half of that found on station. The results also show that the deliberately very high dietary proportion of the test feeds prevented that milk yield remained completely undisturbed. If these dietary proportions should be kept, diets would have to be balanced with ingredients rich in energy.

Acknowledgments Our thanks go especially to the farmers Abu Bakri, Abu Khaled, Dhirar Al Nassani, Fawaz, Mohamed Al Nassani and Said for participating in the present study with intensive and thorough work and being generous during the entire experiment. We thank Dr. Safouh Rihawi for his assistance in diet formulation, Monika Zaklouta for her assistance in coordinating the experiments, Ahmad Sawass for coordinating the milk sampling and Ali Al Jassim for supervising the feed mixing and distribution to the farms. We are grateful to all technicians and workers at ICARDA for their great help in the animal experiments and laboratory analyses.

Conflict of interest None.

\section{References}

Abbeddou, S., Rihawi, S., Iñiguez, L., Zaklouta, M., Hess, H.D. and Kreuzer, M., 2011a. Ruminal degradability, digestibility, energy content, and influence on nitrogen turnover of various Mediterranean by-products in fat-tailed Awassi sheep. Animal Feed Science and Technology, 163, 99-110.

Abbeddou, S., Rischkowsky, B.A., Richter, E.K., Hess, H.D. and Kreuzer, M., 2011b. Modification of milk fatty acid composition by feeding forages and agro-industrial by-products from dry areas to Awassi sheep. Journal of Dairy Science, 94, 4657-4668.

AOAC. 1997. Official Methods of Analysis. Association of Official Analytical Chemists, Arlington, VA.

Chilliard, Y., Glasser, F., Ferlay, A., Bernard, L., Rouel, J., and M. Doreau. 2007. Diet, rumen biohydrogenation and nutritional quality of cow and goat milk fat. European Journal of Lipid Science and Technology, 109:828-855.

Chiofalo, B., Liotta, L., Zumbo, A. and Chiofalo, V., 2004. Administration of olive cake for ewe feeding: effect on milk yield and composition. Small Ruminant Research, 55, 169-176.

Council for International Organizations of Medical Sciences and the International Council for Laboratory Animal Science. 2012. International Guiding Principles for Biomedical Research Involving Animals. grants.nih.gov/grants/olaw/Guiding_Principles_2012.pdf (accessed on 21 August 2014).

DACH (German, Austrian and Swiss Societies of Nutrition) (2000). Referenzwerte für die Nährstoffzufuhr. Umschau Braus, Frankfurt/ Main, Germany.

Faye, B., Konuspayeva, G., Narmuratova, M., Serikbaeva, A., Musaad, A.M. and Mehri, H., 2013. Effect of crude olive cake supplementation on camel milk production and fatty acid composition. Dairy Science and Technology, 93, 225-239.

Gómez-Cortés, P., Frutos, P., Mantecón, A.R., Juárez, M., de la Fuente, M.A. and Hervás, G., 2008. Addition of olive oil to dairy ewe diets: effect on milk fatty acid profile and animal performance. Journal of Dairy Science, 91, 3119-3127.

Hadjipanayiotou, M., 1999. Feeding ensiled crude olive cake to lactating Chios ewes, Damascus goats and Friesian cows. Livestock Production Science, 59, 61-66.

Hilali, M., Iñiguez, L., Knaus, W., Schreiner, M., Wurzinger, M., and Mayer, H.K., 2011. Dietary supplementation with nonconventional feeds from the Middle East: Assessing the effects on physicochemical and organoleptic properties of Awassi sheep milk and yogurt. Journal of Dairy Science, 94, 5737-5749.

Jutzeler van Wijlen, R.P. and Colombani, P.C., 2010. Grass-based ruminant production methods and human bioconversion of vaccenic acid with estimations of maximal dietary intake of conjugated linoleic acids. International Dairy Journal, 20, 433-448.

Molina-Alcaide, E. and Yáñez-Ruiz, D., 2008. Potential use of olive byproducts in ruminant feeding: a review. Animal Feed Science and Technology, 147, 247-264.

Molina-Alcaide, E., Morales-García, E.Y., Martín-García, A.I., Ben Salem, H., Nefzaoui, A. and Sanz-Sampelayo, M.R., 2010. Effects of partial replacement of concentrate with feed blocks on nutrient utilization, microbial $\mathrm{N}$ flow, and milk yield and composition in goats. Journal of Dairy Science, 93, 2076-2087.

Romano, R., Masucci, F., Giordano, A., Musso, S.S., Naviglio, D., Santini A. 2010. Effect of tomato by-products in the diet of Comisana sheep on composition and conjugated linoleic acid content of milk fat. International Dairy Journal, 20, $858-862$.

Romero-Huelva, M., Ramos-Morales, E. and Molina-Alcaide, E., 2012. Nutrient utilization, ruminal fermentation, microbial abundances, and milk yield and composition in dairy goats fed diets including 
tomato and cucumber waste fruits. Journal of Dairy Science, 95, 6015-6026.

SAS. 2009. SAS/STAT User's Guide, version 9.2. SAS Institute, Cary, NC. Taheri, M.R., Zamiri, M.J., Rowghani, E. and Akhlaghi, A., 2013. Effect of feeding olive-pulp ensiled with additives on feedlot performance and carcass attributes of fat-tailed lambs. Tropical Animal Health and Production, 45, 345-350.

Terramoccia, S., Bartocci, S., Taticchi, A., Di Giovanni, S., Pauselli, M., Mourvaki, E., Urbani, S. and Servil, M., 2013. Use of dried stoned olive pomace in the feeding of lactating buffaloes: Effect on the quantity and quality of the milk produced. Asian-Australasian Journal of Animal Science, 26, 971-980.

Tilley, J.M.A., Terry, R.A., 1963. A two-stage technique for the in vitro digestion of forage crops. Journal of the British Grassland Society, $18,104-111$
Vargas-Bello-Pérez, E., Vera, R.R., Aguilar, C., Lira, R., Peña, I. and Fernández, J., 2013a. Feeding olive cake to ewes improves fatty acid profile of milk and cheese. Animal Feed Science and Technology, 184, 94-99.

Vargas-Bello-Pérez, E., Vera, R.R., Aguilar, C., Lira, R., Peña, I., Valenzuela, A. and Cerda, H., 2013b. Effect of dietary inclusion of lampante olive oil on milk and cheese fatty acid profiles of ewes. Grasas y Aceites, 64, 295-303.

Vasta, V., Nudda, A., Cannas, A., Lanza, M. and Priolo, A., 2008. Alternative feed resources and their effects on the quality of meat and milk from small ruminant. Animal Feed Science and Technology, 147, 223-246.

Vasta, V. and Luciano, G., 2011. The effects of dietary consumption of plants secondary compounds on small ruminants' products quality. Small Ruminant Research, 101, 150-159. 